\title{
CONTRIBUTION TO NEW CALCULATIONS OF PREHEATING AND DIFFERENTIATION TEMPERATURES USING LAGRANGE INTERPOLATION
}

\author{
Originalni naučni rad / Original scientific paper \\ UDK / UDC: 621.791
}

Rad primljen / Paper received:

Oktobar 2020

Ključne reči: Zavarivanje, temperatura predgrevanja, aproksimacija, vreme

\section{Rezime}

$\mathrm{U}$ radu se daje prikaz hronologije kako se do sada određivalo kritično vreme hlađenja i temperatura predgrevanja kod zavarivanja. Autor rada uvodi jedan nov pristup u izračunavanju temperature predgrevanja koristeći iskustva iz stanja tehnike kao i svoje dugogodišnje rezultate istraživanja na polju zavarivanja. Ranija rešenja su se bazirala na 2D i 3D Rosenthalovom modelu izračunavanja kritičnog vremena hlađenja i pripadajuće temperature predgrevanja i poboljšane izraze koje je koristio British Standard. Ovaj rad koristi potrebna iskustva iz termije i odgovarajućih disciplina matematike. Problemi koji se javljaju i sprečavaju efikasno dobijanje rešivih izraza na prost i elementaran način, autor ovog rada to rešava na jedan potpuno nov i inventivan način.

\section{Uvod}

Rad je nastao analizom i studiranjem literature date u [1-5]. Posebno valja izložiti rezultate velikih istraživača prikazanih u [6-10] čiji su doprinosi omogućili istraživanja istraživačima u oblasti termije.

Autor ovog rada je istraživao značajan broj stručnih i naučnih radova koji se bave određivanjem kritičnog vremena hlađenja i temperature predgrevanja od kojih treba istaći radove prikazane u referencama [10-24] rada. U ovim radovima se koriste teorijski modeli i formule, paketi za simulaciju, rezultati iz prakse, upotrebljava se određivanje navedenih veličina na osnovu ekvivalenta ugljenika ili ekvivalenta CE, kao i druga razna iskustva iz prakse.

\author{
Adresa autora / Author's address: \\ $1^{*}$ Prof. Dr. Univerzitet u Beogradu, Visoka tehnička škola $u$ \\ Beogradu \\ KKorespondirajući autor; E-mail: milicevic.miroslav@mts.rs
}

Keywords: Welding, preheating temperature, approximation, time, new expression

\begin{abstract}
This paper presents a chronology of how the critical cooling time and preheating temperature in welding have been determined so far. The author of this paper introduces a new approach in calculating preheating temperature using prior art experience as well as his long-term research results in the field of welding. Earlier solutions were based on Rosenthal's 2D and 3D model for calculating the critical cooling time and the corresponding preheating temperature and the improved expressions used by the British Standard. This paper uses the necessary experience in thermal and the corresponding disciplines of mathematics. Problems that occur and prevent efficient obtaining of solvable expressions in a simple and elementary way, the author of this paper solves it in a completely new and inventive way.
\end{abstract}

Pošto su se dosadašnje formule za proračun bitnih komponenti termičkih procesa pokazale grubim u smislu tačnosti i rešivosti, autor je korišćenjem brojne i izabrane literature iz matematike i numeričke analize [25-34] izveo proste analitičke izraze za temperaturu predgrevanja koji će biti od velike koristi istraživačima i tehnolozima koji se bave tehnologijom zavarivanja.

Inventivnim rezultatima su doprineli rezultati koje je postigao autor ovog rada učestvujući u publikovanju radova [35-40] sa koautorima ili samostalnim istraživanjima. Korisno su poslužili i izlaganje i rezultati radova [41-42] koji su publikovani u renomiranom časopisu iz oblasti zavarivanja gde su dati teoretski i praktični rezultati. 


\section{Nov model izračunavanja temperature predgrevanja zavarivanja}

Raspodela temperature u ploči koja se zavaruje se može opisati Furijeovom jednačinom

$\frac{\partial \mathrm{T}}{\partial \mathrm{t}}=\mathrm{a}\left(\frac{\partial^{2} \mathrm{~T}}{\partial \mathrm{x}^{2}}+\frac{\partial^{2} \mathrm{~T}}{\partial \mathrm{y}^{2}}\right)$,

gde je $a=\frac{\lambda}{c \gamma}$ - koeficijent toplotne provodnosti, cspecifična toplota i $\gamma$-specifična masa.

Koristeći iskustva iz [6-9] rešenje Furijeove jednačine se svodi na

$\mathrm{T}(\mathrm{r}, \mathrm{x})=\frac{\mathrm{q}}{2 \pi \lambda} \exp \left(-\frac{\mathrm{vx}}{2 \mathrm{a}}\right) \mathrm{K}_{0}\left[\mathrm{r}\left(\frac{\mathrm{v}^{2}}{4 \mathrm{a}^{2}}+\frac{\mathrm{b}}{\mathrm{a}}\right)\right]^{0,5}$

gde je $\mathrm{K}_{0}$ modifikovana Beselova funkcija II vrste $\mathrm{i}$ nultog reda.

Kada je intenzitet unosa količine toplote q veći, prethodna jednačina se svodi na

$T\left(\mathrm{y}_{0}, \mathrm{t}\right)=\frac{\mathrm{q}}{\mathrm{vd} \sqrt{4 \pi \lambda c \gamma t}} \exp \left(-\frac{\mathrm{y}^{2}}{4 \mathrm{at}}-\mathrm{bt}\right)$

i ova jednačina predpostavlja da je toplotni fluks duž ose $x$ nula. Za slučaj da je najveća brzina hlađenja u zoni vara, može se pisati $y=0$ i zanemariti taj član u eksponentu, te je

$\mathrm{T}(\mathrm{t})=\frac{\mathrm{q}}{\mathrm{vd} \sqrt{4 \pi \lambda c \gamma t}}$

Pri zavarivanju bitne su veličine vremena pri kome se prolazi hlađenjem, posle zavarivanja, na temperaturama od $800{ }^{\circ} \mathrm{C}$ i $500{ }^{\circ} \mathrm{C}$.

Do sada su se u literaturi [1-10], ovi režimi opisivali i istraživali pomoću 2D i 3D Rosenthalovog modela jednačina. Tako je za 2D model

$\mathrm{t}_{8,5}=\frac{\mathrm{q}^{2}}{4 \pi \lambda \gamma \mathrm{cd}^{2}}\left[\frac{1}{\left(500-\mathrm{T}_{\mathrm{p}}\right)^{2}}-\frac{1}{\left(800-\mathrm{T}_{\mathrm{p}}\right)^{2}}\right]$

gde su: $d$ debljina materijala, $q$ ulazna toplota, $T_{p}$ temperatura predgrevanja, $t_{8,5}$ kritično vreme hlađenja, $\lambda$ termalna provodnost $u\left[\mathrm{Js}^{-1} \mathrm{~m}^{-10} \mathrm{C}\right], \mathrm{c}$ specifična toplota $u\left[\mathrm{Jkg}^{-10} \mathrm{C}^{-1}\right] \mathrm{i} \quad \gamma$ je specifična težina $\mathrm{u}\left[\mathrm{kgm}^{-3}\right]$.

Za 3D model za izračunavanje kritičnog vremena hlađenja u funkciji temperature predgrevanja postoji u literaturi izraz:

$\mathrm{t}_{8,5}=\frac{\mathrm{q}}{2 \pi \lambda}\left[\frac{1}{500-\mathrm{T}_{\mathrm{p}}}-\frac{1}{800-\mathrm{T}_{\mathrm{p}}}\right]$

Za izbor modela pri zavarivanju se koristi jednačina $\mathrm{d}_{\mathrm{gr}}=\left[\frac{\mathrm{q}}{\rho \mathrm{c}}\left(\frac{1}{500-\mathrm{T}_{\mathrm{p}}}\right)+\left(\frac{1}{800-\mathrm{T}_{\mathrm{p}}}\right)\right]^{0,5}$,

tako da se ispituje debljina trake koja se zavaruje, te ako je jednaka ili manja od veličine date izrazom (7) tada se uzima model tipa 2D, u suprotnom se koristi 3D model. Sve ovo se vrši da bi se poboljšala tačnost.

Jednačine (5) i (6) su se upotrebljavale u dugom vremenskom periodu, a da pri tome se nije pristupalo njihovom kritičkom ocenjivanju pri praktičnim primenama gde se podrazumeva ceo opseg korišćenja promenljivih i za razne vrste zavarivanja.

$U$ referencama [1-9] se koriste relacije (5) i (6), što dokazuje korišćenje ovih relacija sve do vremena istraživanja u ovom radu.

$\mathrm{U}$ manjem broju radova se konstatuje odstupanje izračunatog vremena hlađenja, ali se ne daju ispravke ni potvrde i dokazi za tačnost rešenja. Zato je zbog odstupanja $u$ tačnosti vremena hlađenja, pri izradi British Standarda za ovu oblast zavarivanja [28], izvršena ispravka u smislu tačnijeg izračunavanja što se daje jednačinama (8) i (9) respektivno za 2D i 3D model.

$\mathrm{t}_{8,5}=\left(4300-4,3 \mathrm{~T}_{\mathrm{p}}\right) \frac{\mathrm{q}^{2}}{\mathrm{~d}^{2}}\left[\frac{1}{\left(500-\mathrm{T}_{\mathrm{p}}\right)^{2}}-\frac{1}{\left(800-\mathrm{T}_{\mathrm{p}}\right)^{2}}\right]$

$\mathrm{t}_{8,5}=\left(6700-5 \mathrm{~T}_{\mathrm{p}}\right) \times \mathrm{xq}\left[\frac{1}{500-\mathrm{T}_{\mathrm{p}}}-\frac{1}{800-\mathrm{T}_{\mathrm{p}}}\right]$

Kroz primenjena istraživanja numeričkim izračunavanjima pronalazi se da i relacije (8) i (9) na nekim delovima opsega korišćenja znatno odstupaju.

\section{Apoksimativno određivanje temperature predgrevanja primenom metode Lagranžeove interpolacije}

Za tačno određivanje kritičnog vremena hlađenja i temperature predgrevanja autor ovog rada je sa koautorima u priloženim radovima pored egzaktnog izračunavanja primenjivao $i$ iterativne metode kod rešavanja transcedentnih jednačina. Ova rešenja se mogu naći i grafičkim putem ali to nije uvek dobar slučaj kada se radi o pripremi tehnologije raznih zavarivanja.

Zato će se relacija (3) rešavati tako što će se transedentni deo koji sadrži kvadratni koren i eksponencijalnu funkciju aproksimirati primenom Lagranžeove interpolacije kako je to ilustrovano u referencama [25-34]. Pošto se kod većine zavarivanja proces $\mathrm{T}(\mathrm{t})$ završava do vremena od 50 sekundi to će se posmatrati ovaj opseg za aproksimiranje kroz sledeći primer.

\section{Primer 1}

Projektovati zavarivanje čeličnih limova debljine $7,4 \mathrm{~mm}$ i unete količine toplote $q_{1}=13610 \mathrm{~J} / \mathrm{cm}$. Izračunati optimalnu temperaturu predgrevanja čeličnog materijala kako bi se dobio kvalitetan var a da se pri tome ne remeti struktura osnovnog materijala u proizvodu koji se zavaruje. Koristi se čelik kritične brzine hlađenja $15^{\circ} \mathrm{C} / \mathrm{s}$.

Da bismo došli do brzine hlađenja, ona je sada vodeća i ne uzima se u obzir kritično vreme 
hlađenja $t_{8 / 5}$, jednačinu (3) iz ovog rada ćemo diferencirati po t čime se dobija

$\mathrm{W}_{0}=\frac{\mathrm{q}}{\mathrm{vd} \sqrt{4 \pi \lambda \mathrm{c \gamma t}}} \exp \left(-\frac{\mathrm{y}^{2}}{4 \mathrm{at}}-\mathrm{bt}\right) \frac{\sqrt{\mathrm{t}}}{\mathrm{t}}\left[\left(\frac{\mathrm{y}^{2}}{4 \mathrm{at}^{2}}-\mathrm{b}\right) \sqrt{\mathrm{t}}-\frac{1}{2 \sqrt{\mathrm{t}}}\right](10)$

što posle svođenja i izvlačenja dela za temperaturu

T daje

$\mathrm{W}_{0}=\mathrm{T}(\mathrm{y}, \mathrm{t})\left[\frac{1}{2 \mathrm{t}}\left(\frac{\mathrm{y}^{2}}{2 \mathrm{at}}-1\right)-\mathrm{b}\right]$

Relacija (11) definiše brzinu hlađenja materijala bez ogrančenjai ona će poslužiti da se izračuna temperatura predgrevanja. Za slučaj $y=0$, jednačina (11) postaje

$\mathrm{W}_{0}=-\mathrm{T}(\mathrm{t})\left[\frac{1}{2 \mathrm{t}}+\mathrm{b}\right]$.

U realciji (12) koja je posve originalna budući da sadrži osnovni izraz za temperaturu $T$ proizilazi da izraz u srednjoj zagradi faktički predstavlja"operator diferenciranja". Na ovaj način je omogućeno da se na skraćen način izračunava brzina hlađenja, a preko nje i drugi potrebni elementi sve do temperature predgrevanja.

Problem u osnovi je što se u izrazu za temperaturu javlja kvadratni koren i eksponencijalni član što jednačinu čini transcedentnom. Ta jednačina se može rešavati grafički, iterativno ili primenom nekih gotovih paketa koji se koriste u računarima.
Zato ćemo mi za naš primer 1 izdvojiti poznate elemente od ovih koji treba da se aproksimiraju, tako da jednačina (3) postaje

$$
\mathrm{T}(\mathrm{t})=\mathrm{k} \frac{\mathrm{e}^{-\mathrm{bt}}}{\sqrt{\mathrm{t}}}(13)
$$

što posle smene poznatih veličina daje

$\mathrm{T}(\mathrm{t})=4015 \frac{\mathrm{e}^{-\mathrm{bt}}}{\sqrt{\mathrm{t}}}$

Iz jedačine (14) se vidi da je promenljiv deo sa kvadratnim korenom i eksponencijalni član, te ćemo izvršiti aproksimaciju pomoću Lagranžeovog interpolacionog polinoma III stepena kako bismo mogli lakše da analitički rešavamo projektni zadatak.

$U$ opštem slučaju za nepoznatu funkciju $f(x)$ koja je zadata tabelarno sa pripadajućim numeričkim vrednostima,kod Lagranžeove interpolacije[2534],određuje se rešenje u obliku polinoma:

$y=\sum_{i=0}^{m} a_{i} x^{i}$

gde se određuju nepoznati koeficijenti $a_{i}$.

Za različite vrednosti vremena $t$ izračunava se vremenski zavistan član jednačine (14) i tako izabranim parovima, posle izračunavanja grešaka aproksimacije i većih numeričkih izračunavanja, $(5 ; 0,419),(20 ; 0,174),(35 ; 0,109)$ i $(50 ; 0,075)$ formira se Lagranžeov interpolacioni polinom oblika:

$$
P_{3}(t)=0,419 \frac{(t-20)(t-35)(t-50)}{(5-20)(5-35)(5-50)}+0,174 \frac{(t-5)(t-35)(t-50)}{(20-5)(20-35)(20-50)}+0,109 \frac{(t-5)(t-20)(t-50)}{(35-5)(35-20)(35-50)}+0,075 \frac{(t-5)(t-20)(t-35)}{(50-5)(50-20)(50-35)}
$$

što posle sređivanja daje

$$
P_{3}(t)=-0,000007359 t^{3}+0,000841545 t^{2}-0,03350835 t+0,56641575
$$

Funkcija data izrazom (17) aproksimira naš transcedentni član jednačine (14) sa nekom greškom koja mora biti tehnološki opravdana, $\mathrm{s}$ jedne strane, a s druge strane ona mora analitički biti rešiva. U ovom slučaju pošto se radi o polinomu trećeg stepena on je rešiv pomoću poznatih, u matematičkoj teoriji, Kardanovih obrazaca.

Tako se može naći vreme $t_{8}$ koje predstavlja vreme kada na $T(t)$ dijagramu se dostigne vrednost od $800^{\circ} \mathrm{C}$, kao i vreme $t_{5}$ kada se postiže vrednost temperature od $500^{\circ} \mathrm{C}$, čija razlika određuje dobro poznato kritično veme hlađenja u termiji poznato kao $t_{8 / 5}$.
Ali, da bismo izveli obrazac za brzinu hlađenja potrebno je polinom (17) diferencirati po $t$, tako da se dobija izraz

$W(t)=-0,000022077 t^{2}+0,00168309 t-0,03350835$

Kod izračunavanja vrednosti izraza (17) i (18) potrebno in je pomnožiti konstantom $\mathrm{k}=4015$ kako bismo dobili nominalne veličine za pravu temperaturu,odnosno za brzinu hlađenja.

$U$ Tabeli 1za naš primer zavarivanja iz prakse su date vrednosti za temperature hlađenja i brzine hlađenja, gde je sa "T" označena tačna vrednost a sa "A" aproksimativna. 
Tabela 1. Vrednosti temperature i brzine hlađenja za egzaktne vrednosti i približne dobijene Lagranžeovim interpolacionim polinomom

\begin{tabular}{cccc}
\hline$t(s)$ & Temperatura $T^{T}(t)\left({ }^{0} C\right)$ & Temperatura $T^{A}(t)\left({ }^{0} C\right)$ & Brzina hlađenja $W^{A}(t) W^{\top}(t)\left({ }^{0} C / s\right)$ \\
\hline 10 & 1120 & 1236 & $-58 /-70$ \\
\hline 15 & 859 & 916 & $-53 /-39$ \\
\hline 20 & 698 & 696.7 & $-35 /-26$ \\
\hline 25 & 586 & 561 & $-21 /-19$ \\
\hline 30 & 506 & 481 & $-11.6 /-14.76$ \\
\hline 35 & 438 & 435.4 & $-6.6 /-11.7$ \\
\hline 40 & 385 & 405 & $-6.05 /-9.6$ \\
\hline 45 & 341 & 369 & $-9.93 /-8.06$ \\
\hline 50 & 301 & 301.1 & $-18.25 /-6.78$ \\
\hline 55 & 272 & 180 & $-31 /-5.87$ \\
\hline 60 & 245 & 17.7 & $-48.2 /-5.1$ \\
\hline \multicolumn{4}{c}{}
\end{tabular}

$\mathrm{U}$ navedenoj tabeli pored temperatura su date i brzine hlađenja respektivno za tačan izraz i za aproksimacioni interpolacioni polinom III stepena.Studiranjem nominalno dobijenih rezultata vidi se da su temperature približne, dovoljno za inženjersku praksu u ovom tehnološkom slučaju, međutim primetno je veliko odstupanje u brzinama hlađenja.

Tabela 2. Procentualno odstupanje tačne i aproksimacione temperature hladjenja

\begin{tabular}{cccc}
\hline$t(s)$ & Temperatura $T^{T}(t)\left({ }^{0} \mathrm{C}\right)$ & Temperatura $T^{A}(t)\left({ }^{0} \mathrm{C}\right)$ & Relat.greska (\%) \\
\hline 10 & 1120 & 1236 & 10 \\
\hline 15 & 859 & 916 & 6.6 \\
\hline 20 & 698 & 696.7 & 0.2 \\
\hline 25 & 586 & 561 & 4.3 \\
\hline 30 & 506 & 481 & 4.9 \\
\hline 35 & 438 & 435.4 & 0.6 \\
\hline 40 & 385 & 405 & 5.2 \\
\hline 45 & 341 & 369 & 8.2 \\
\hline 50 & 301 & 301.1 & 0.0 \\
\hline 55 & 272 & 180 & 33.8 \\
\hline & Napomena: indeksom "T" označena tačna vrednost a sa "A" aproksimativna
\end{tabular}

Tabela 3. Procentualno odstupanje prvog izvoda (brzine hladjenja) tačne i aproksimacione formule

\begin{tabular}{cccc}
\hline$t(s)$ & Tacni prvi izvod $\left({ }^{\circ} \mathrm{C} / \mathrm{s}\right)$ & Aproksimacioni prvi izvod $\left({ }^{\circ} \mathrm{C} / \mathrm{s}\right)$ & Relat.greska (\%) \\
\hline 10 & -70 & -58 & 20.68 \\
\hline 15 & -39 & -53 & 35.89 \\
\hline 20 & -26 & -35 & 34.6 \\
\hline 25 & -19 & -21 & 10.53 \\
\hline 30 & -14.76 & -11.6 & 21.46 \\
\hline 35 & -11.7 & -6.6 & 43.58 \\
\hline 40 & -9.6 & -6.05 & -36.97 \\
\hline 45 & -8.06 & -9.93 & 23.20 \\
\hline 50 & -6.78 & -18.25 & -169.2 \\
\hline 55 & -5.87 & -31 & -428.1 \\
\hline 60 & -5.1 & -48.2 & -845.1 \\
\hline & Napomena: indeksom "T" označena tačna vrednost a sa "A" aproksimativna
\end{tabular}


Uvidom $u$ vrednosti relativnog odstupanja $u$ procentima za brzine hlađenja, tj. prvih izvoda intepolacionog polinoma, konstatuje se velika pogreška u izračunavanju prvog izvoda iako je funkcija iz izraza (18) diferencijabilna i ispunjava sve uslove za diferenciranje po referencama iz priloga ovog rada.Tako se i čvornoj tački interpolacionog polinoma za vreme od $50 \mathrm{~s}$ ima relativno odstupanje od oko $170 \%$, pri 55 s čak $428 \%$ što je nedopustivo veliko odstupanje.Prosečno odstupanje brzine hlađenja u opsegu $10 \mathrm{~s}$ do $50 \mathrm{~s}$ iznosi $44^{\circ} \mathrm{C} / \mathrm{s}$ što direktno ima za posledicu netačno određivanje temperature predgrevanja.

Problem odstupanja brzina hlađenja dovodi u pitanje tačnost diferenciranja, te da bi se to istražilo konstruisaćemo pripadajuće grafičke zavisnosti za temperature hlađenja i brzine hlađenja koje su numeričli date u Tabelama $1 \mathrm{i} 2 . \mathrm{Na}$ Slici 1.su dati grafici za temperature hlađenja i oni pokazuju opravdanst i valjanost aproksimacije što su potvrdile i vrednosti iz ranije navedenih tabela, gde posle 50s interpolacioni polinom daje značajnija odstupanja (kriva 2).

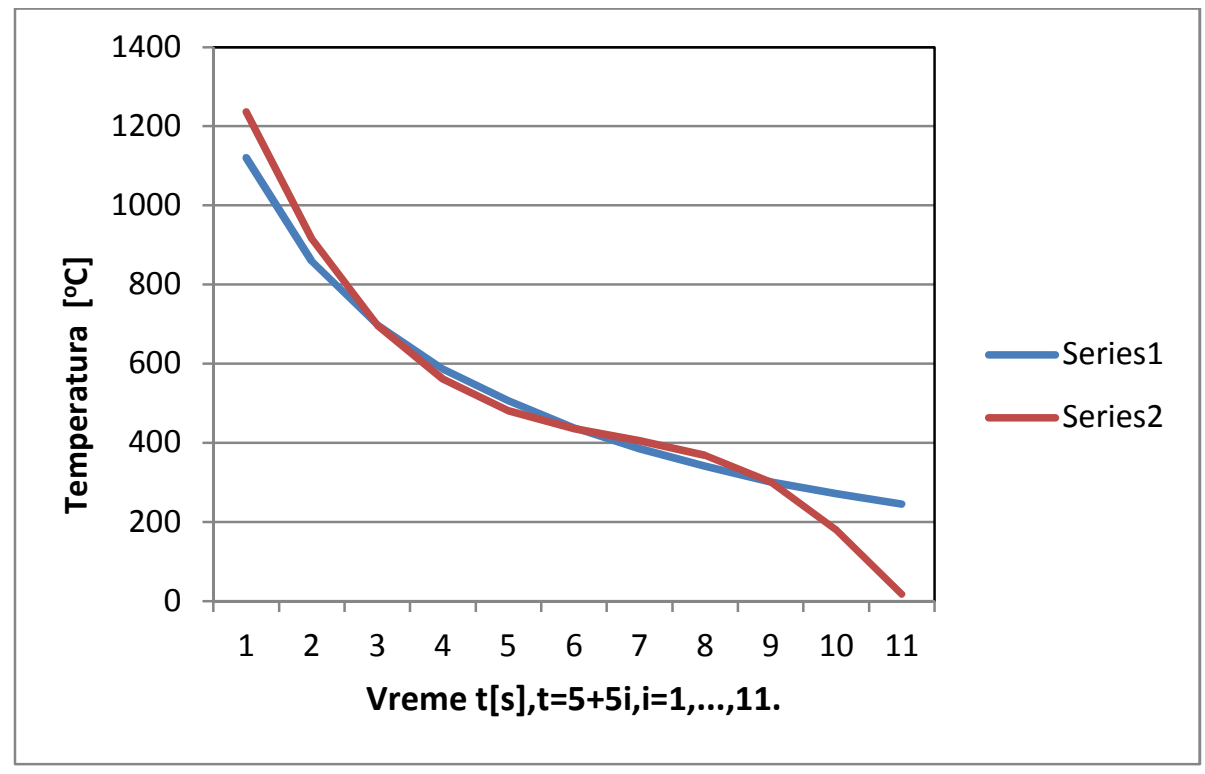

Slika 1. Graficki prikaz temperature hlađenja po tačnoj (kriva 1) i aproksimacionoj formuli (kriva 2)

Slika 2. prikazuje,pored temperatura hlađenja i grafičke zavisnosti za brzine hlađenja što i želimo da još podrobnije ispitamo.

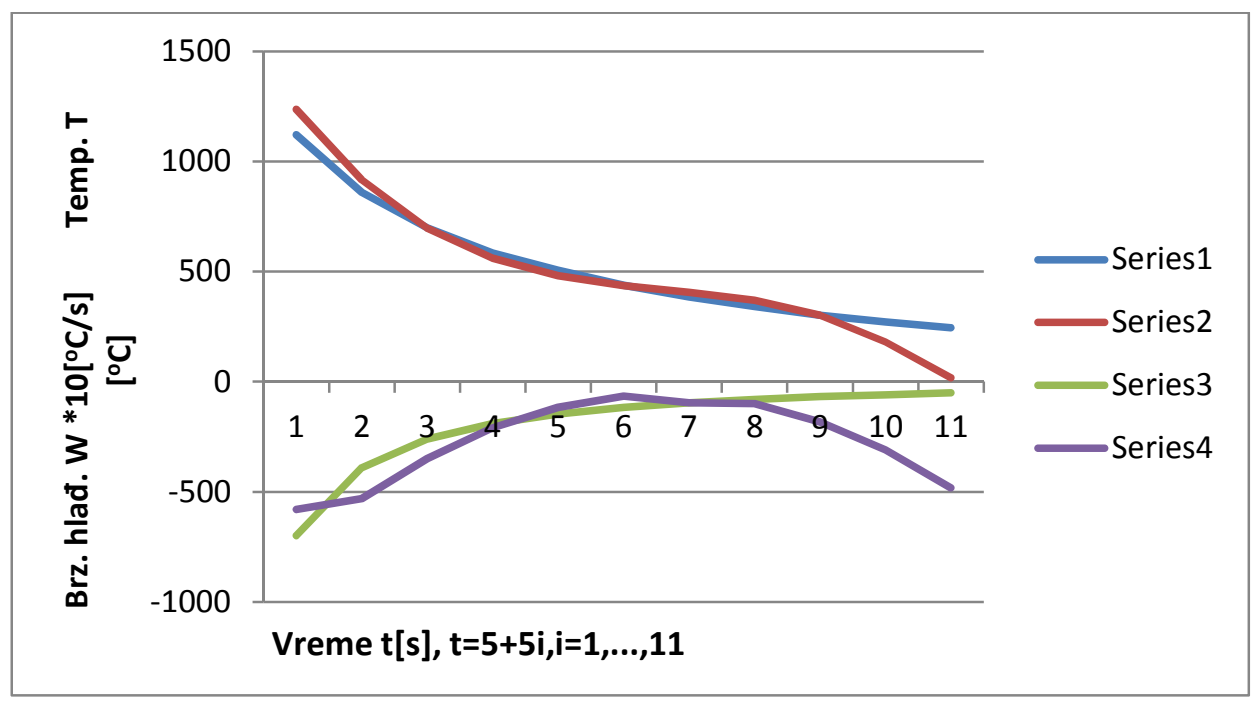

Slika 2. Grafički prikaz tačnih (kriva1) i aproksimativnih (kriva 2) temperatura i tačne brzine hlađenja(kriva 3) i aproksimativne brzine hlađenja (kriva 4) 
$\mathrm{Na}$ Slici 2.kriva "3" predstavlja prvi izvod tačne temperature, a kriva "4" predstavlja prvi izvod aproksimacione krive za temperaturu i dokazuje se netačnost.Radi bolje vidljivosti vrednosti za brzine hlađenja su povećane deset puta, to je negativni deo ordinatne ose.Ovo će se potkrepiti grafikom sa slike Slike 3, gde je veoma primetno veliko odstupanje krive "2" koja predstavlja prvi izvod interpolacionog polinoma (17) u obliku (18).

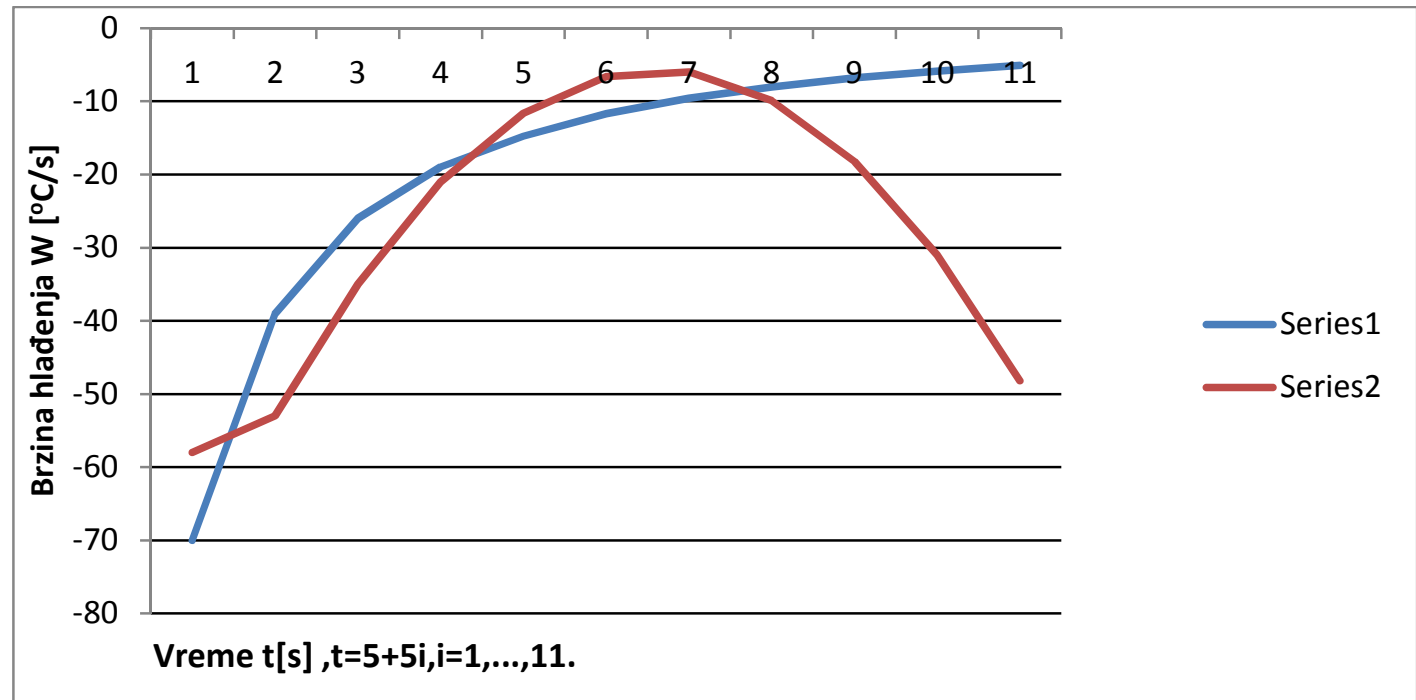

Slika 3. Grafici prvih izvoda (brzina hlađenja) po tačnoj (kriva 1) i interpolacionoj formuli (kriva 2)

Sa Slike 3 se vidi da brzina hlađenja dobijena diferenciranjem interpolacionog polinoma se smanjuje, dostiže ekstremum, i ponovo raste. Sve ovo pored velikog nominalnog odstupanja u odnosu na tačnu krivu, stvara još veći problem budući da ponovo raste posle ekstrema. Zbog ovoga bi se dobila dva rešenja kada bi se rešavala kvadratna jednačina i to bi dovelo do zabune. Nažalost oba rešenja bi bila netačna, a za male vrednosti brzine hlađenja ne bi se našlo rešenje.

\section{Analiza rezultata i diskusija}

$U$ prethodnom delu rada je aproksimirana zavisnost za temperaturu $T(t)$ čime su stvoreni uslovi za prosta analitička izračunavanja temperature $u$ funkciji vremena i kritičnog vremena hlađenja.

Prikazaće se posebni grafici za temperaturu i brzinu hlađenja za egzaktne zavisnosti i aproksimacione, jer to do sada nije urađeno. $\mathrm{Na}$ Slici 4. je prikazan grafik za tačne vrednosti a na Slici 5. za aproksimacione vrednosti.

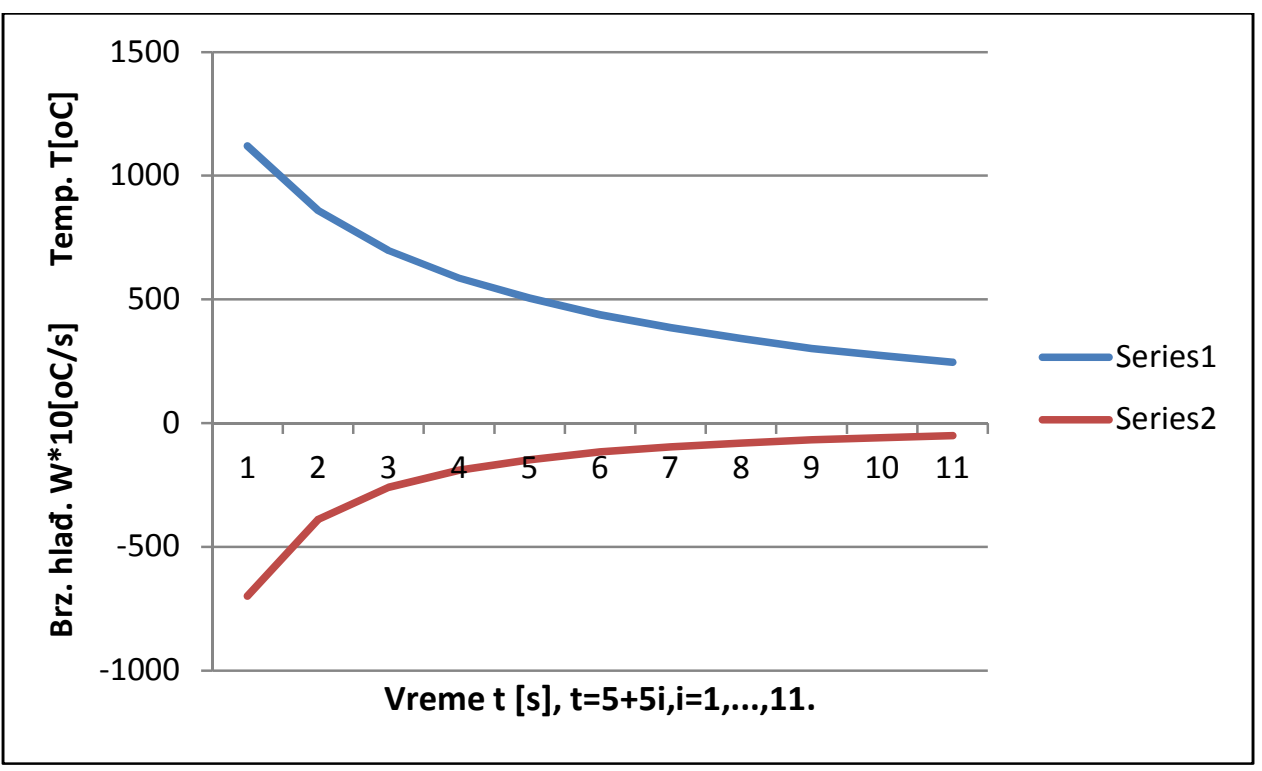

Slika 4. Grafičke zavisnosti za temperaturu (kriva 1) $i$ brzinu hlađenja (kriva 2) po tačnim formulama 


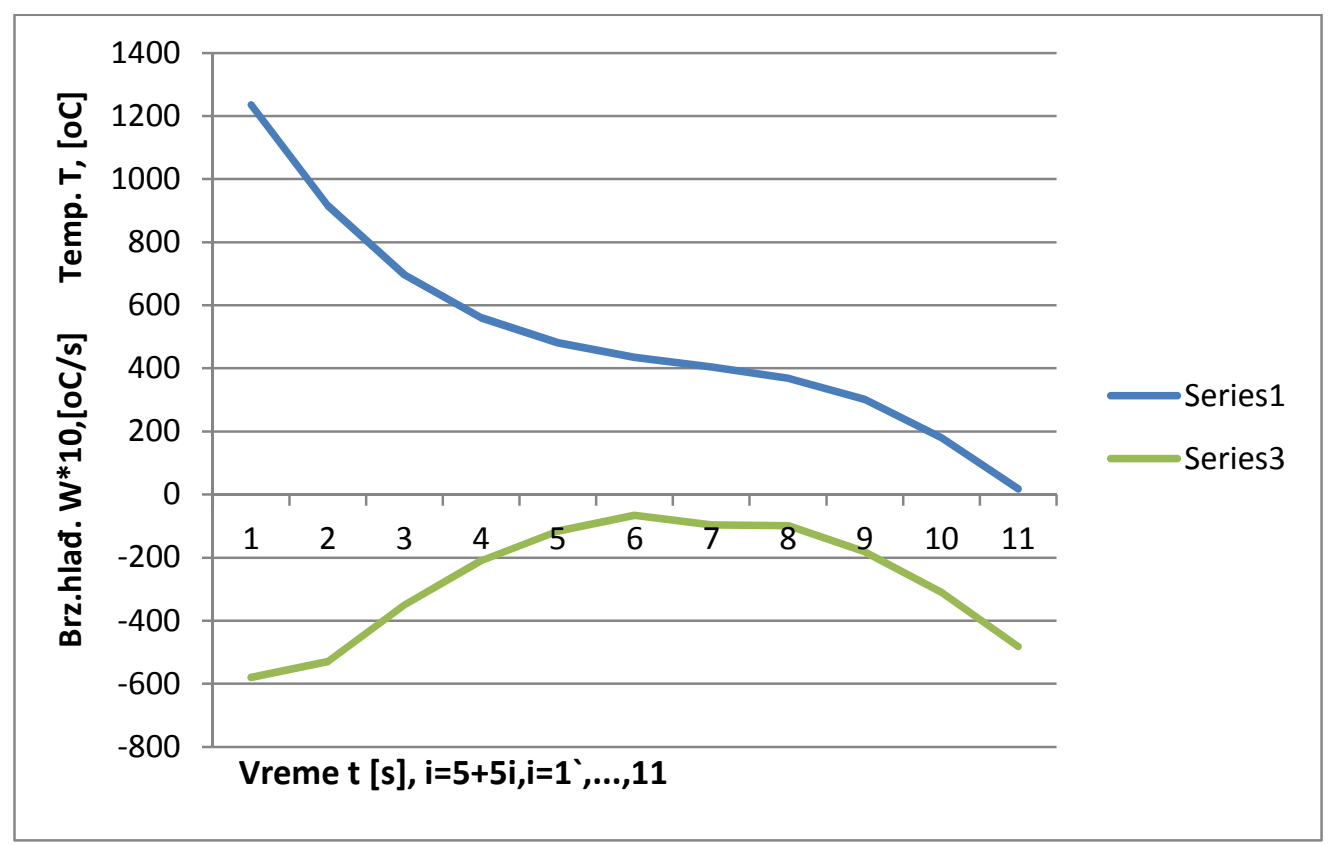

Slika 5.Grafički prikaz aproksimativnog modela za temperaturu (kriva 1) i brzinu hlađenja (kriva 2)

Za grafike saSlika 4 i 5 važi da je za brzinu hlađenja zbog povećanja rezolucije uvećane su vrednosti za deset puta. Zbog potvrđivanja netačnosti prvih izvoda interpolacionih polinoma konstruisaće se grafik dat na Slici 6. gde je ilustrovan relativni procentaulni podatak netačne vrednosti u odnosu na tačnu koja je dobijena diferenciranjem transcedentne jednačine za temperaturu (3) predstavljene izrazom (10).

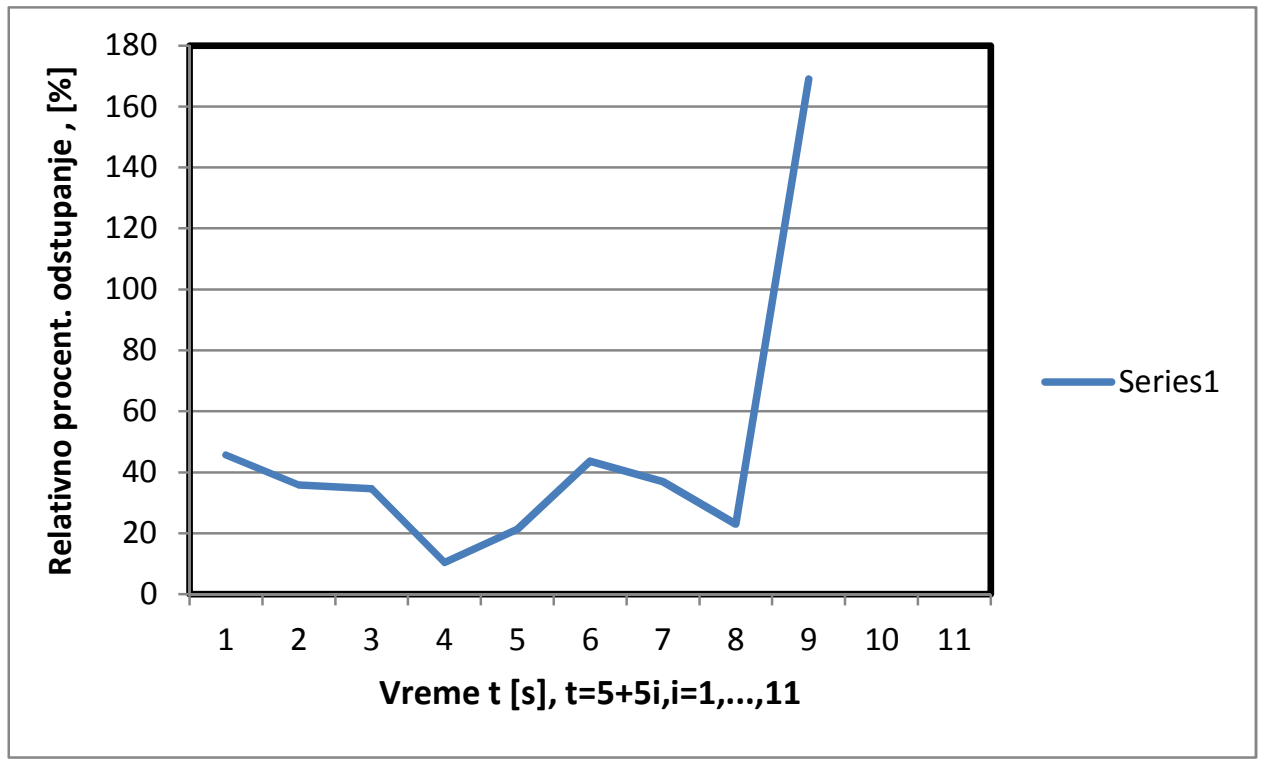

Sika 6. Grafik procentualnog odstupanja prvog izvoda (brzine hladjenja) egzaktnog izraza i izvoda aproksimacionog polinoma u funkciji vremena

Grafik sa Slike 6. dokazuje neispravnost nalaženja prvog izvoda koja ne može biti tolerisana jer pokazuje veliku netačnost kada se diferencira dobijena formula nastala putem interpolacije. Ovo je autor ovog rada utvrdio da se to isto dešava i kod drugih inetrpolacionih polinoma. To se isto potvrđuje i analitički kada se izraz za brzinu hlađenja izjednači sa zadatom vrednošću, najčešće ne može se naći tačno rešenje, a ponekad se dobijaju konjugovano kompleksna rešenja.

Radi rešavanja nastalog problema, autor ovog rada, na bazi višegodišnjih iskustava, uvešće jednu posve novu invenciju, tako što budući da je $\mathrm{T}(\mathrm{t})=\mathrm{P}_{3}(\mathrm{t})+\mathrm{R}$

a $R$ je dozvoljiva greška aproksimacije, to izraz za brzinu hlađenja je sada 
$\mathrm{W}_{0}=-\mathrm{P}_{3}(\mathrm{t})\left[\frac{1}{2 \mathrm{t}}+\mathrm{b}\right]$.

Za primer br. 1 , se zamenom da je $W_{0}=15^{\circ} \mathrm{C} / \mathrm{s}$, i za $\mathrm{P}_{3}(\mathrm{t})$ iz (17) dobija vrednost za vreme $\mathrm{t}_{\mathrm{p}} \mathrm{u}$ iznosu od 29.5s karakteristično i ključno u određivanju temperature predgrevanja. Smenom ove vrednosti za t u (17) dobija se temperatura

$\mathrm{T}(\mathrm{t})=500^{\circ} \mathrm{C}(21)$

čija razlika do temperature od $800{ }^{\circ} \mathrm{C}$ predstavlja temperaturu predgrevanja

$\mathrm{T}_{\mathrm{p}}=800-500=300^{\circ} \mathrm{C}$

Zavarivanje iz primera 1 treba prethodno ostvariti tako da se izvrši predgrevanje na temperaturi $300^{\circ} \mathrm{C}$. Ovim je na originalan način, i pored problema sa netačnim diferenciranjem, predstavljen originalan tačan analitički algoritam koji će koristiti u rešavanju problema iz termije uvođenjem novog tipa diferenciranja. Novo diferenciranje se primenjuje od izraza dobijenog posle diferenciranja tačnog izraza $\mathrm{T}(\mathrm{t})$, tako što se tim novim izrazom, a bez $\mathrm{T}(\mathrm{t})$, množi interpolacioni polinom dobijen Lagranžeovom interpolaciojom.

Za slučaj primene izraza (18) dobile bi se dve vrednost temperature predgrevanja, što stvara problem odluke koja da se uzme, s jedne strane, i velika odstupanja u posmatranom intervalu, prosečno od oko 44\%, s druge strane,onemogućavaju primenu u praksi. To bi za posledicu imalo loš var sa visokim procentom ugljenika i krtu strukturu po [4].

\section{Zaključak}

Ovaj rad je rezultat teoretsko primenjenih istraživanja u dužem vremenskom periodu. Obrađeno je i prezentovano kretanje u teoriji i praksi, kada je pronađeno da ima više formula za izračunavanje ključnih veličina u termiji, kojom prilikom je utvrđeno da ne daju precizne rezultate na svim segmentima izračunavanja koji su potrebni $\mathrm{u}$ termiji kod zavarivanja. Te formule se i danas navode u brojnim radovima, knjigama pa čak i u disertacijama bez identifikovanja tačnosti rezultata. A kasnije se primenju gotovi kupljeni softverski paketi za simulaciju i izračunavanje kako bi se stvorio privid primene postojeće teorije. Autor ovog rada je sa koautorima i sam u brojnim svojim

\section{Literatura}

[1] Welding Handbook, Vol. 3, 7th ed., American Welding Society, Miami, FL, 1980,pp. 170-238.

[2] Welding Handbook,Ninth Edition, Volume 4, Materials and Applications, Part 1, American Welding Society, Annette O'Brien - Editor,Miami, FI, USA, p.860,2011

[3] Sindo Kou, Welding Metallurgy, Second Edition, Wiley-Interscience, Hobeken, New Jersey, USA,p.466,2003 radovima [35-40] ukazivao na to nudeći nove i veoma precizne zavisnosti i postuke za izračunavanje. Budući da je za rešavanje transcedentnih jednačina autor koristio iterativne metode koje su davale precizne rezultate karakterističnih veličina i to kritičnog vremena hlađenja i temperature predgrevanja [40] gotovo istih kao što to daje FEM metoda. To znači da rezultate koje je autor ovog rada dobio u ponuđenoj referenci, gotovo da su isti kao oni dobijeni FEM metodom.

Zato je autor u ovom radu prišao numeričkom izračunavanju,koja zamenjuju transcedentne jedančine za temperaturu i brzinu hlađenja, primenom Lagranžeove interpolacije. Ova interpolacija je dala korisne rezultate za izračunavanje temperature hlađenja. Međutim, nažalost kada se pokušalo izvesti izraz za brzinu hlađenja, diferenciranjem interpolacionog polinoma, otkriveno je i pored diferencijabilnosti izraza prvi izvodi su bili neprecizni. Taj nedostatak je uočen i kod aproksimacije sa drugim polinomima.

Ovaj problem je nagnao autora ovog rada da jednom novom ivencijom dobije tačan prvi izvod (što predstavlja brzinu hlađenja), tako što je direktno množio interpolacioni polinom izdvojenim izrazom za diferenciranje koji potiče od matične funkcije. Rezultati su bili ispravni što je potvrđeno brojnim tabelama i graficima. Dobijeni analitički izrazi za temperaturu hlađenja i brzinu hlađenja nisu transcedentni, lako su rešivi kod primenjenih istraživanja i primene u praksi.

\section{Zahvalnost}

Autor rada se zahvaljuje glavnom uredniku časopisa Zavarivanje i zavarene konstrukcije na uspešnom vođenju i kreiranju profila ovog časopisa, kao i ostalim saradnicima na visokoj profesionalnosti i spremnosti za saradnju. Autor rada želi da ovaj rad posveti Isacu Newton-u, budući da je njegovo veličanstvo uvelo $u$ matematiku još pre 350 godina elemente više matematike kroz poznatu $u$ literaturi Newton Lajbnicovu relaciju za diferenciranje koja je osnov za nalaženje izvoda i integrala.

[4] H. Schuman: Metallography, Leipzig, VEB Deutcher Verlag fur Grunstoffindustrie (1989)

[5] Shamov, N.A., et al., High Frequency Metal Welding, Masinostroenie, Leningrad, Russia, 199

[6] Rykalin,N.N., Calculation of Heat Flow in Welding, Trans. Z. Paley and C. M.Adams,Jr., Document 212350-74, 1974, International Institute of Welding,

[7] Rykalin, N. N., Nikolaev, A. V. Welding Arc Heat Flow. Welding in the World, 9, 3/4(1971), pp.112-132. 
[8] Rosenthal, D. The Theory of Moving Source of Heat and its Application to Metal Transfer. Transations ASME, 43, 11(1946), pp. 849-866.

[9] Christensen B.N., Davies V.D.L., Gjermundsen K., Distribution of temperatures in arc welding, British Welding Journal, February (1965), p.p. 54 to 75

[10] Milićević M., The Application of a New Formula of Nakaoka Coefficient in HF Inductive Welding, Journal of Mechanical Engineering 56 (2010), 78,p.p. 483-488

[11] Poorhaydari K., Patchett B.M., Ivey D.G., Estimation of Cooling Rate in the Welding of Plates with Intermediate Thickness, Welding Journal, October (2006), p.p. 149 to155

[12] Lazic, V. N., et al, Theoretical-Experimental Determining of Cooling Time $(\mathrm{T}(8 / 5))$ in Hard Facing of Steels for Forging Dies, Thermal Science, 14, (2010), 1, pp. 235-246

[13] Lazic, V. N., et al.: Numerical Analysis of Temperature Field During Hardfacing... Thermale Science: Vol. 18, Suppl. 1, (2014), pp.113-120

[14] Meseguer-Valdenebro, J.L. et al.: Calculation of t8/5 by Response Surface. Termale Science:Vol. 18, Suppl. 1, (2014), pp. S149 - S158

[15] Jovičić R., Prokić Cvetković R., Popović O., Milošević, Metode za izračunavanje temperatura predgrevanja pri zavarivanju čelika povišene i visoke čvrstoće, Zavarivanje i zavarene konstrukcije, br.3, 2016, pp. 113 to 119

[16] Jovičić. R., Erić Cekić O., Petrović S., Štrbački S., Jovičić D., Definisanje parametara zavarivanja pomoću vremena hlađenja $u$ intervalu temperatura 800 do $500{ }^{\circ} \mathrm{C}$, Zavarivanje i zavarene konstrukcije, br.4, 2016, pp.149 to 156

[17] Ito, Y., Bessyo, K., Weld crackability formula of high strenght steels, J. Iron and Steel Inst., Jap., No 13., 1972.

[18] Yurioka N.,Tadashi K., A Chart Method to Determine Necessary Preheat Temperature in Steel Welding, Quarterly Journal of Japan Welding Society, Vol.13,No.3, pp.347 to 357, 1995

[19] Yurioka N., Physical Metallurgy of Steel Weldability, ISIJ International, Vol.41, 2001, no.6, pp. 566-570

[20] Kasuza T.,Yurioka N.,Determination of Necessary Preheat Temperature to Avoid Cold Cracking under Varying Ambient Tempearture, ISIJ International, Vol.35, 1995,No.10, pp.1183-1189

[21] Merchant S.Y.,Investigation on Effect of Heat Input on Cooling Rate and Mechanical Property (Hardness) of Mild Steel Weld Joint by MMAW Process, IJMER, Vol.5, Iss.3, Mar. 2015, pp.34-41

[22] Merchant S.Y.,An Overview on Effect of Preheating on Cold Cracking ofLow Alloy Steel and Stainless Steel Weld Joint, IJAIEM, Vol.4, Issue 4, April 2015, pp.70-77

[23] Poorhaydary K.,Patchett B.M.,Ivey D.G.,Estimation of Cooling rate in the Welding of Plates with Intermediate Thickness, Welding Research, October 2005, pp.149-155 BRITISH STANDARD BS EN 1011-2:2001, Incorporating
Amendment No.1, Welding- recommendations for welding of metallic materials, Part 2: Arc welding of ferritic steels, The Eropean Standard EN 10112:2001

[24] Pejović T., Matematička analiza II, treće izdanje, Naučna knjiga, Beograd,1961, Srbija

[25] Pejović T., Matematićka analiza V, peto izdanje, Građevinska knjiga,Beograd, 1978, Srbija

[26] Mitrinović S.D.,Kečkić D.J., Jednačine matematičke fizike, Građevinska knjiga,1972, Beograd, Srbija

[27] Mitrinović S.D., Uvod u specijalne funkcije, Matematički metodi u fizici i tehnici, Građevinska knjiga,Beograd, 1972, Srbija

[28] Mihailović D., Janić R.R., Elementi matematićke analize, četvrto izmenjeno izdanje, Naučna knjiga, Beograd, 1974, Srbija

[29] Mitrinović S.D., Kompleksna analiza, treće izmenjeno i dopunjeno izdanje, Građevinska knjiga, Beograd, 1973, Srbija

[30] Demidovič P. B., Maron A. I., Computational Mathematics, Mir Publishers, Moskow, 1973

[31] Milovanović V.G., Đorđević Ž. Radoslav, Matematika za studente tehnićkih fakulteta, I deo, IP Nauka,1992, Beograd, Srbija

[32] Milovanović V.G., Numerička analiza I deo, Univerzitet u Nišu, 1979, Niš, Srbija

[33] Milovanović V.G., Numerička naliza II deo, treće izdanje, Naučna knjiga, 1991, Beograd, Srbija

[34] Milićević, M., Radaković, Z., Quality Improvement of Steel Pipes by Seam Welding with New MagnetoDielectric Impeder, Materials Transactions, 47, 06, The Japan Institute of Metals, (2006), 1464-s to 1468-s.

[35] M. Milicević and V. Milicević: Impeder for HF Inductive Welding of Steel Tubes, IEE Proceedings, Science, Mesurement and Technology, vol.149.(2002),No.3, p.p. 113-116

[36] M. S. Milićević and V. M. Milićević: European Transactions on Electrical Power, 14 No. 2 (2004) 111-118.

[37] MilićevićM. et al., Defects identification of the hihg frequency inductive welding, Mining and Metallurgy Engineering Bor, 2006, no.2

[38] NejkovićM.V., MilićevićS.M., Radaković Z., Temperature distribution in thermal processes, Welding in the World, DOI 10.1007/s40194-0180672-9, (2018)

[39] Nejković M.V.,Milićević S.M., Radaković Z., New method of determining of cooling time and preheating temperature in Arcwelding, Thermal Science, DOI/10.2298/ TSCl1 80330297N,(2018)

[40] Vukićević M., Petrović Z., Bjelić M., Đurić S., Statički i dinamički modeli u zavarivanju, Zavarivanje i zavarene konstrukcije, br.1, 2009, str.159 do 164

[41] Katavić B., Jegdić B., Odanović Z., Hut M., Mladenović M., Jaković D., Ristivojević M., Predviđanje optimalnih parametara interventnog reparaturnog zavarivanja čelika $13 \mathrm{CrMn} 4$ analitičkim metodama, Zavarivanje i zavarene konstrukcije, br.3, 2010, str. 91 do 96 